\title{
Electric field and infrared radiation in the troposphere before earthquakes
}

\author{
V. A. Liperovsky ${ }^{1}$, C.-V. Meister ${ }^{2}$, V. V. Mikhailin ${ }^{4}$, V. V. Bogdanov ${ }^{3}$, P. M. Umarkhodgaev ${ }^{4}$, and E. V. Liperovskaya ${ }^{1}$ \\ ${ }^{1}$ Institute of Physics of the Earth of the Russian Academy of Sciences, Bolshaya Gruzinskaya 10, 123995 Moscow, Russia \\ ${ }^{2}$ Institut für Kernphysik, Technische Universität Darmstadt, Schlossgartenstr. 9, 64289 Darmstadt, Germany \\ ${ }^{3}$ Institute of Cosmophysical Research and Radio Wave Propagation, Far Eastern Branch of the Russian Academy of Sciences, \\ 684034 Petropavlovsk-Kamchatsky, Russia \\ ${ }^{4}$ Institute of Nuclear Physics, Lomonossov State University, Moscow, Russia
}

Received: 15 October 2010 - Revised: 19 August 2011 - Accepted: 16 October 2011 - Published: 2 December 2011

\begin{abstract}
Some years ago, a model of the generation of local electric fields in the atmosphere a few days before earthquakes and up to a few days after the seismic shock was proposed. In the model, the generation of the electric fields occurs because of an increased ionisation intensity of the atmosphere in the presence of aerosols. The generation of the electric field is the result of the fact that the larger aerosols, which are mainly negatively charged, have a larger velocity of gravitational precipitation than the smaller, which are mainly positively charged aerosols. The ionisation in such atmospheric regions is caused by radon, the concentration of which increases in earthquake preparation regions. The formation of mosaic-likely distributed areas of electric fields with intensities of $3 \times 10^{2}-10^{5} \mathrm{Vm}^{-1}$ and, on the other hand, large areas with increased electrical conductivity cause a series of physical effects, e.g. the occurrence of infrared emissions with a specific spectrum, which may be studied using earth-based, atmospheric and satellite observations. In the present paper, the model of the generation of local electric fields is further developed, improving the description of the force balance on the aerosols in the atmosphere. A recently proposed laboratory experiment is briefly discussed, which is carried out to prove the theoretically predicted intensification of infrared emissions some hours-days before earthquakes. Besides the experiment described, it will be operated on Kamchatka in the near future to scan mosaic-likely distributed regions of electric fields in the atmosphere during earthquake preparation times.
\end{abstract}

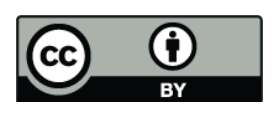

Correspondence to: C.-V. Meister (c.v.meister@ skmail.ikp.phyik.tudarmstadt.de)

\section{Introduction}

Already for $150 \mathrm{yr}$, scientists are attempting to find a way to predict earthquakes using traditional seismological methods. We believe that, in principle, the problem of the longterm prediction of earthquakes is solved. But to predict an earthquake some tenths of hours before the seismic shock remains one of the most important problems of modern geophysics. It has to be noted that for a successful short-time prediction it is not only necessary to perform seismologic investigations, but also multi-directional studies of the physics of earthquakes. Additionally, a complex of various further phenomena connected with the earthquake preparation has to be understood (Liperovsky et al., 1992; Pulinets and Boyarchuk, 2006; Molchanov and Hayakawa, 2008; Meister et al., 2011).

Concerning the physical effects occurring before earthquakes in the troposphere, which are recently studied, one has especially to emphasize the excitation of intensive variations of the quasi-constant electric field, changes of electromagnetic emissions and the occurrence of luminous phenomena at the night-time sky.

In the present paper, former results on electromagnetic emissions and variations of the quasi-constant electric field before strong earthquakes are summarized (Sect. 2). Then, a mechanism is discussed, which describes how infrared (IR) emissions might be generated in the atmosphere before strong earthquakes and how they might be used as earthquake precursors. A corresponding physical model proposed in Liperovsky et al. (2005, 2008a) and Mikhailin et al. (2010) is further developed and corrected (Sect. 3). It is explained which laboratory works were initiated to prove this model. Recently planned experiments to remotely monitor atmospheric IR emissions are briefly discussed (Sect. 4).

Published by Copernicus Publications on behalf of the European Geosciences Union. 


\section{Electromagnetic emissions and quasi-constant electric field before strong earthquakes}

\subsection{Luminous and infrared phenomena}

The appearance of pulses of light and of other luminous phenomena, and the generation of anomalous variations of the electric field by earthquakes have been observed for thousands of years before strong seismic events (Derr, 1973; Fidani, 2010; Grigoriev et al., 1988; Hedervari and Noszticzius, 1985; Sobolev and Demin, 1980). But luminous phenomena before earthquakes occur rather seldom. According to historical sources, pulses of light, most often lasting some seconds, were observed during the last $2000 \mathrm{yr}$ before earthquakes with magnitudes $M>6$ in about 5 per cent of the cases (Papadopoulos, 1999). Investigating equilibrium thermal and IR emissions above the Middle Asian region by satellites analysing daily, night-time, thermal images in the wavelength interval of 10.5-11.3 $\mu \mathrm{m}$ (satellite of "Tairos" series, altitude of about $500 \mathrm{~km}$ ), the existence of anomalies was observed (Gorny et al., 1988). They generally occurred in the intersections of fractures (Eshov and Uzhenko, 1983). But, to solve the problem of earthquake prediction, it is interesting to examine nonequilibrium IR emissions.

It is not easy to find out the physical mechanisms causing luminous and IR effects in the atmosphere before earthquakes. This problem was already discussed by Grigoriev et al. (1988), taking into account different hypotheses. Concerning the IR effects, we recently consider, for example, an unsteady mass input of the lithospheric gas into the atmosphere (see, for example, Shalimov and Gokhberg, 1998), rising fluids which cause the emanation of warm gases (see, for example, Gorny et al., 1998), rising well water levels and changes in the soil moisture (Chadha et al., 2003), diffuse $\mathrm{CO}_{2}$-emanation causing a local greenhouse effect (see, for example, Quing et al., 1991). Further, Freund et al. (2007) suggested that enhanced IR emissions at the Earth's surface arise from charged particles, so-called " $p$-hole charge carriers" (by stress broken initially electrically inactive $p$ hole pairs, e.g. peroxy links $\mathrm{O}_{3} \mathrm{X} / 00 / \mathrm{XO}_{3}\left(\mathrm{X}=\mathrm{Si}^{4+}, \mathrm{AL}^{3+}\right)$ ) from the Earth's crust when rocks are exposed to large stresses before seismic shocks. P-holes can move with velocities of $100-300 \mathrm{~ms}^{-1}$ and they quickly diffuse to rock surfaces, propagate through layers between blocks of rocks and through layers of water. The thermal anomalies occur because of the thermalization of vibrationally excited O-Ostates. Pulinets et al. (2006) supposed that due to the enhanced radon emanation and the air ionisation by the radon, the amount of centres of water vapour condensation increases in the atmosphere. During the condensation, a large amount of latent heat is released giving rise to thermal anomalies.

In the present work, it is also assumed that IR emissions are caused by emanating gases like radon. But additionally an upstreaming of air contributes to the excitation of shorttime electric field pulses. Non-equilibrium IR emissions occur due to these electric fields. The basic concepts of the model were already presented in detail in Liperovsky et al. (2005, 2007a, b, 2008a, b) and are summarized in Sect. 3.

The structure of the luminous regions, described by witnesses and generalised by Derr (1973), very often possesses the form of a half-sphere with a radius of $10-100 \mathrm{~m}$ contacting the Earth's surface. Other forms were single light pulses, fireballs, bands, torches or columns of light. In the mid-sixties, documental proof of luminous effects connected to earthquakes was obtained. In all hypotheses, it was taken into account that the reason for the earthquake lights is an anomalous electric field.

Variations of electric fields are connected with modifications of electrical conductivities and, thus, with changes of the degree of ionisation. Observations of ionized regions in the atmosphere are recently performed by radiolocation. Atmospheric disturbances above the earthquake preparation areas found by radiolocation experiments are analysed, e.g. in the works of Voinov et al. (1992) and Slivinskiy et al. (2008). It is found that reflections from usual nonthunderstorm clouds are rare in the meter region of wavelengths. Reflections from thunderstorm clouds are to be seen as bright fluctuating points on displays. The week before the Spitak earthquake and three days after the earthquake no thunderstorms occurred, the weather was cloudy with little rain, but on the displays of the radiolocation stations fluctuating points were observed in the sectors showing at Spitak. Thus, it might be that there existed an anomalous electric field of seismic origin in the atmosphere before the Spitak earthquake.

\subsection{Variations of the quasi-constant electric field}

Performing experimental research works concerning the anomalies of the vertical electric field in earthquake preparation areas, it was pointed out that long-lasting anomalies of the electric field and vertical currents occur during the first hours - the first tenths of minutes - before seismic shocks at distances of up to $200 \mathrm{~km}$ from the epicentre even when visible sources of an atmospheric nature are missing. There, a direct dependence of the intensity of the anomalous variations from the parameters of the earthquake does not exist (Rulenko et al., 1996). But according to our knowledge, anomalies of the electric field and of vertical currents appearing a few days before earthquakes are only investigated for a small number of events using stationary installations in the near-surface atmosphere.

Rulenko (2000) found that it is reasonable to divide the observed anomalies of the electric field near the Earth's surface into two types. The first type corresponds with the decrease of the intensity of the electric field from values which correspond to good or almost good weather down to a minimum value $E_{\min }$, and a following growth to intensity values which almost equal the preceding level. Therefore, sometimes the value of $E_{\min }$ becomes negative. The characteristic 
time scale of such an anomaly equals $0.3-4 \mathrm{~h}$. The second type may be described as a package of oscillations with a certain number of frequencies which suddenly occur in front of the normal or almost normal atmospheric background electric field. The characteristic time scale of this anomaly is $0.2-$ $4 \mathrm{~h}$, and the period of oscillations is in the interval between a few seconds and 1.5-2 $\mathrm{h}$. The amplitude of the oscillations may be many times larger than the background field.

Experiments related to the measurement and analysis of the variations of the quasi-constant electric field are described in the works by Mikhailov et al. $(2004,2005)$ and by Smirnov (2005). Often the anomalies of the electric field before and immediately after the seismic shock are about 12 orders of magnitude larger than the background values. The most probable value of bay-formed variations at altitudes of some kilometres above the Earth's surface equals 100$300 \mathrm{~V} \mathrm{~m}^{-1}$. Their duration lasts $40-100 \mathrm{~min}$. Such characteristic time scales of non-stationary processes belong to Frenkel clouds (Frenkel, 1949), which are described below.

It is well-known that the breakdown voltage in a cloud equals $3 \times 10^{6} \mathrm{~V} \mathrm{~m}^{-1}$. But at an ionising air radiation, the electric discharges occur at lower fields. Here, cosmic radiation plays a role, which forms small quasi-vertical plasma channels, the so-called "branches of the plasma tree". During a short time-interval, between the branches the vertical component of the electrical conductivity increases. Correspondingly the electric field decreases, and outside of this region the electric field, in contrast, increases. It should be mentioned that the possibility of the occurrence of extensive air showers with energies above $10^{15} \mathrm{eV}$ is large. In a cloud with a ground area of $13 \mathrm{~km}^{2}$ it is about $30 \mathrm{~s}^{-1}$ (Ermakov and Stoshkov, 2003).

The model of the generation of quasi-homogeneous largescale anomalous electric fields in the near-earth atmosphere before earthquakes was developed in the works (Pulinets et al., 2002; Pulinets and Boyarchuk, 2004; Sorokin and Chmyrev, 2002; Smirnov, 1992; Heinke et al., 1995; Sorokin et al., 1998; Sorokin and Jashenko, 2000). This model takes into account the anomalous ionisation at radon emanation from the Earth's core before earthquakes and the hydration process - the attraction of water molecules, which the atmosphere always contains - to the newly formed ions, the formation of ligants, which shelter the charged particles from recombination and make them quasi-stable.

Further, it should be mentioned that, according to Pulinets and Boyarchuk (2004) and Anagnostopoulos et al. (2011), anomalous electric fields above earthquake preparation areas induce electron density irregularities in the ionosphere and a subsequent increase in VLF wave activity in the magnetosphere. The electron cyclotron resonance with the VLF waves may cause velocity changes in the radiation belt electrons, so that these travel downwards to the Earth, contribute there to ionisation processes, and to electromagnetic disturbances in the ionospheric D-layer. As the precipitating electrons possess a fast eastward drift, the detection of such disturbances may be used for the study of long-distance seismic shocks (Liperovskaya et al., 2011).

\section{Model of the non-stationary Frenkel generator}

The model of the non-stationary Frenkel generator of electric fields proposed in Liperovsky et al. (2005; 2007a, b; 2008a, b) is based on the degassing of the Earth's core, the injection of radon into the atmosphere and an upward directed atmospheric wind. The vertical particle motion in the atmosphere is strengthened by the local heating processes at the Earth's surface above the seismic regions, and it also grows because of water condensation at aerosols, the concentration of which is increased by the degassing. So, the model suggests a nonhomogeneous, anomalous ionisation of the atmosphere at altitudes of $10-20 \mathrm{~km}$ above impending seismic shocks. An electric field with characteristic dimensions in the order of hundreds of kilometres occurs and mosaic-likely distributed, so-called Frenkel areas of non-stationary electric fields are formed in the atmosphere above seismic regions. The electric fields have time scales of 30-100 min. The Frenkel areas are the source of non-equilibrium propagatable IR emissions in the wavelength region of $8-15 \mu \mathrm{m}$. They can be used in the system of earthquake prediction. The entity of the described processes of the model is illustrated in Fig. 1.

Thus, according to the model, it was assumed that under the condition that the electric fields - the precursors of earthquakes in the near-earth atmosphere - are too small to cause a breakthrough (occurring at $3 \times 10^{6} \mathrm{~V} \mathrm{~m}^{-1}$ ) and the excitation of visible emissions $\left(3 \times 10^{5} \mathrm{~V} \mathrm{~m}^{-1}\right)$, so they might nevertheless be strong enough to generate non-equilibrium IR emissions. But, in reality, all appeared to be more difficult. Let us consider some details of the model, and let us develop the model further.

$\alpha$-particles emitted during radioactive decays, e.g. by radon, transfer its energy due to repeated interactions with the atmospheric molecules, ionise the molecules and excite them. Besides the accretion of water molecules to the molecular ions proceeds. As a result, light (less than 9 water molecules bound) and heavy ions form. Then the formation and electrification of aerosols starts. Then the increase of their dimensions and numbers follows at sufficiently high humidity. The model allows us to explain the appearance of aerosols which are formed in regions of increased electrical conductivity (Smirnov, 1980).

In this connection, the existence of an experimentally observed and theoretically founded regularity (Rusanov, 1978) is of importance, according to which small aerosols are, above all, positively charged and the large ones possess a negative charge.

Furthermore, the ions are divided by gravity and an electric field $E_{\max } \sim V \rho_{+} / S$ appears. $\rho_{+}$is the volume density of the positive charge, $V$ designates the volume of the pancakeformed cloud of charges and $S$ is its cross-section. Thus, the 
maximum amplitude of the pulse of the vertical local electric field in the atmosphere is determined by the ratio of the mean density of the positive charge to the unity area of the projection of the cloud to the Earth's surface. So, the formation of the mosaic-likely distribution in the atmosphere nonstationary Frenkel areas of the electric field proceeds, where in the upper part of the cloud a positive charge occurs, and in the lower part a negative one is forming.

Thus, according to the model, the total electric field $\boldsymbol{E}_{\text {tot }}$ in a Frenkel area is the sum of the main background electric field $\boldsymbol{E}_{o}\left(\approx 130 \mathrm{~V} \mathrm{~m}^{-1}\right)$ and the additional field $\boldsymbol{E}$ caused by the charge separation in the clouds (i.e. by a Frenkel generator).

\subsection{Extended model considering the aerosol acceleration}

Using the model of the plain capacitor, the dynamics of the electric field $E$ may be described by the equation (Liperovsky et al., 2005)

$$
\frac{\partial E}{\partial t}=\frac{1}{\varepsilon_{o}} V_{-} Q^{-} N_{\mathrm{a}}^{-}-\frac{\lambda_{o}}{\varepsilon_{o}} \frac{n}{n_{o}} E .
$$

In Eq. (1), the first term on the right side takes the downward motion of the large, negatively charged aerosols into account and the second term considers the decrease of the electric field by the compensating electric current. $V_{-}, N_{\mathrm{a}}^{-}$and $Q^{-}$ are the velocity, number density and the charge of the large negatively charged aerosols of radius $R$ and mass density $\rho_{\mathrm{a}}$. $\lambda_{o}$ and $n_{o}$ designate the electrical conductivity and the ion density of the background plasma (i.e. without aerosols) at ionisation rate $q_{i}^{o}$. $n$ is the ion density in the system with additional ionisation (e.g. by radon) at a larger ionisation rate $q_{i} . \varepsilon_{o}$ is dielectric susceptibility of the vacuum.

Combining Eq. (1) with the balance of gravity, viscose and electric forces on the large aerosols,

$\frac{4}{3} \pi R^{3} \rho_{\mathrm{a}} g-6 \pi R \eta V_{-}-Q^{-} E=0$.

the maximum amplitude of the electric field may be estimated by

$$
\begin{array}{r}
E_{\mathrm{M}}=\frac{A}{B+C}, \quad A=\frac{2 R^{2} \rho_{a} g Q^{-} N_{\mathrm{a}}^{-}}{9 \eta} \\
B=\lambda_{o} \frac{n}{n_{o}}, \quad C=\frac{\left(Q^{-}\right) 2 N_{\mathrm{a}}^{-}}{6 \pi \eta R} .
\end{array}
$$

$g \approx 10 \mathrm{~ms}^{-2}$ is the gravity acceleration, $\rho_{\mathrm{a}}$ - the mass density of the large aerosols - and $\eta$ the viscosity of the air. The density of the positively or negatively charged background ions $n_{o}$ is almost equal to $\sqrt{q_{i}^{o} / \alpha}$. In case of the model condition (see Liperovsky et al., 2005)

$\alpha n \ll \beta\left(N_{\mathrm{a}}^{+}+N_{\mathrm{a}}^{-}\right)$,

$n$ may be estimated by

$n=q_{i} /\left(\beta N_{\mathrm{a}}^{+}\right)$. $\alpha$ is the ion-ion recombination coefficient, $\beta$ the recombination coefficient taking the interaction between ions and aerosols into account and $N_{\mathrm{a}}^{+}$designates the number density of the small positively charged aerosols. Thus,

$B=\lambda_{o} \frac{\sqrt{\alpha} q_{i}}{\sqrt{q_{i}^{o}} \beta N_{\mathrm{a}}^{+}}$,

or, taking Eq. (4) into account, one has

$B<B^{*}=\frac{\lambda_{o} q_{i}}{\sqrt{q_{i}^{o} \alpha} n}$.

Substituting the relation (7) into Eq. (3), one finds a minimum value of $E_{\mathrm{M}}$, which is independent of the recombination coefficient $\beta$. Using the typical atmospheric parameters (Liperovsky et al., 2005) $q_{i}^{o}=10^{7} \mathrm{~m}^{-3} \mathrm{~s}^{-1}$ and $q_{i}=\left(10^{8}-10^{10}\right) \mathrm{m}^{-3} \mathrm{~s}^{-1}$, and choosing for the aerosols the parameters $N_{\mathrm{a}}^{-}=10^{9} \mathrm{~m}^{-3}, Q^{-}=2000 e,(e-$ electron charge), $\alpha=10^{-13} \mathrm{~m}^{3} \mathrm{~s}^{-1}$, and $\rho_{\mathrm{a}}=2.5 \times 10^{3} \mathrm{~kg} \mathrm{~m}^{-3}$, one obtains $A=10^{-10} \mathrm{~A} \mathrm{~m}^{-2}, B^{*}=\left(2 \times 10^{-13}-2 \times 10^{-11}\right)$ $\mathrm{AV}^{-1} \mathrm{~m}^{-1}$, and $C=3 \times 10^{-13} \mathrm{AV}^{-1} \mathrm{~m}^{-1}$. Then, the minimum value of $E_{\mathrm{M}}$ has to be larger than (200-300) $\mathrm{Vm}^{-1}$ at $q_{i}=10^{8} \mathrm{~m}^{-3} \mathrm{~s}^{-1}$, and larger than only $5 \mathrm{Vm}^{-1}$ at $q_{i}=$ $10^{10} \mathrm{~m}^{-3} \mathrm{~s}^{-1}$. The last, larger $q_{i}$-values correspond to radon influences considered also in Pulinets and Boyarchuk (2004) and Pulinets et al. (2006).

In the article by Liperovsky et al. (2005), estimating the maximum electric field, $C$ was neglected, as $N_{\mathrm{a}}^{-} \ll N_{\mathrm{a}}^{+}$ (because of the quasi-neutrality of the air), and $B$ was taken for $q_{i}=10^{8} \mathrm{~m}^{-3} \mathrm{~s}^{-1}$. The other plasma parameters were $N_{\mathrm{a}}^{+}=10^{10} \mathrm{~m}^{-3}, \beta=2 \times 10^{-12} \mathrm{~m}^{3} \mathrm{~s}^{-1}$. Then, $B=5 \times 10^{-15} \mathrm{AV}^{-1} \mathrm{~m}^{-1}$ and $E_{\mathrm{M}}=2 \times 10^{4} \mathrm{Vm}^{-1}$. But, at maximum $q_{i}$ of $10^{10} \mathrm{~m}^{-3} \mathrm{~s}^{-1}, B$ may reach values of $5 \times 10^{-13} \mathrm{AV}^{-1} \mathrm{~m}^{-1}$. Moreover, estimating additionally $C$, one finds for the parameters used in Liperovsky et al. (2005) $C=3 \times 10^{-13} \mathrm{AV}^{-1} \mathrm{~m}^{-1}$. Under such conditions, one would observe only electric fields of about $300 \mathrm{Vm}^{-1}$. C strongly depends on the aerosol density and charge. Reducing both parameters by a factor of two, $C$ would equal $3.75 \times 10^{-14} \mathrm{AV}^{-1} \mathrm{~m}^{-1}$, and one would already observe $600 \mathrm{Vm}^{-1}$. A further increase of $E_{\mathrm{M}}$ will occur at somewhat larger aerosol radii. On the other hand, the recombination coefficient $\beta$ also strongly depends on the type of aerosols, for water aerosols $\mathrm{H}_{3} \mathrm{O}^{+}\left(\mathrm{H}_{2} \mathrm{O}\right)_{5}$, it is of the order of $\beta=10^{-11} \mathrm{~m}^{3} \mathrm{~s}^{-1}$ (Pulinets and Boyarchuk, 2004), and values smaller by one order will be obtained for $B$. Altogether, estimating the electric fields excited by Frenkel generators in the lower atmosphere, $C$ cannot be neglected in Eq. (3). Besides, to develop the theory further, there should be more careful observations made of atmospheric aerosol parameters. Further, it is assumed that the electric fields excited by the Frenkel generator in the atmosphere are on the order of $10^{3}-10^{5} \mathrm{Vm}^{-1}$. 


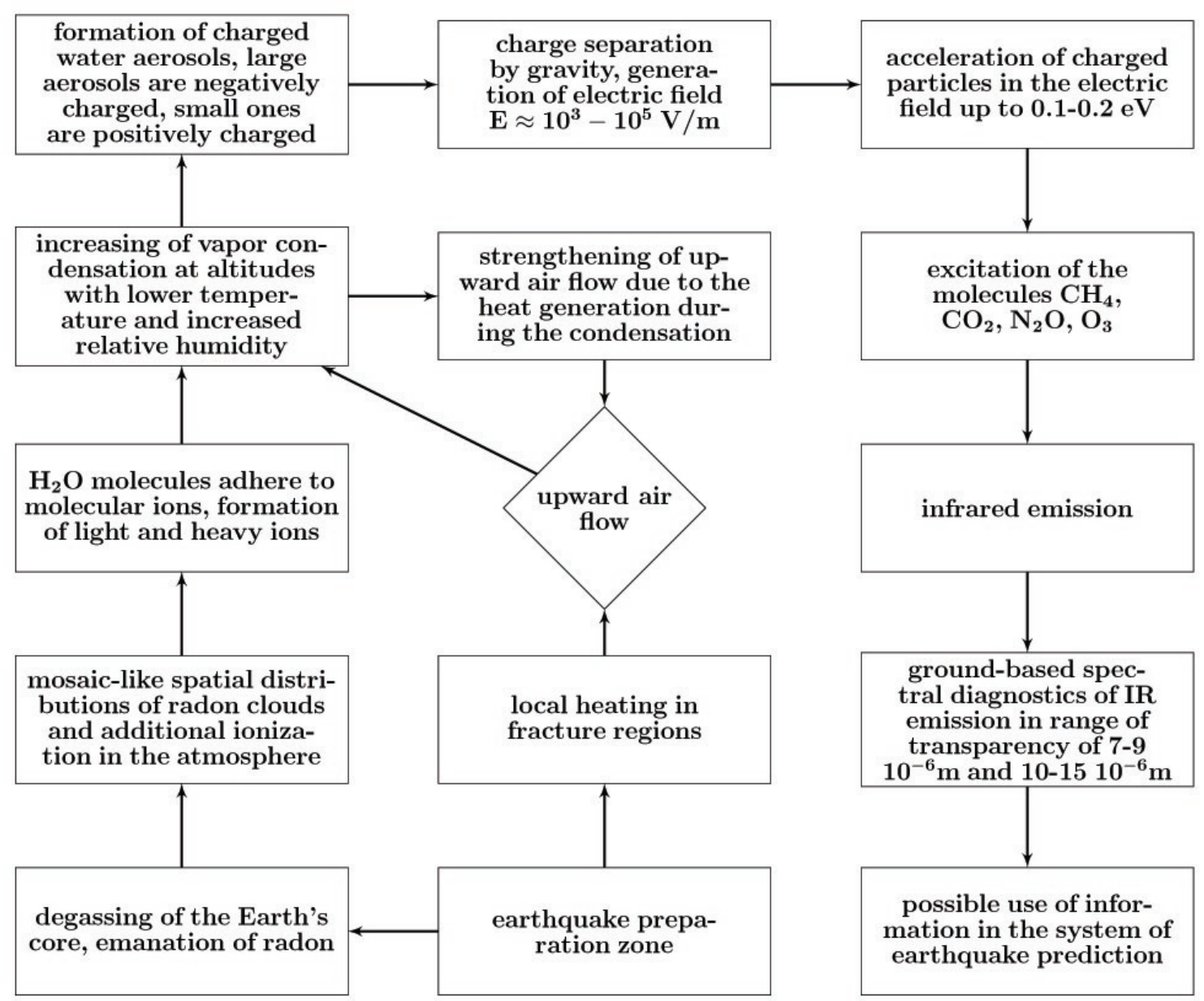

Fig. 1. Sequence of processes resulting in the generation of infrared emissions in the atmosphere before earthquakes.

\subsection{Generation of infrared emissions}

It is suggested that in a certain moment of time, at a given altitude, an electric field $\boldsymbol{E}$ is generated in a Frenkel area. Because of this field, an electric current appears, which causes a decrease in the field and the charge separation. The electric current may be presented as a sum of five components,

$\boldsymbol{j}_{\text {tot }}=\boldsymbol{j}_{\mathrm{li}}+\boldsymbol{j}_{\mathrm{mi}}+\boldsymbol{j}_{\mathrm{e}}+\boldsymbol{j}_{\mathrm{ai}}+\boldsymbol{j}_{\mathrm{hi}}$

where $\boldsymbol{j}_{\text {li }}$ is the current of the light ions, $\boldsymbol{j}_{\mathrm{mi}}-$ of the molecular ions, $\boldsymbol{j}_{\mathrm{e}}-$ electrons, $\boldsymbol{j}_{\mathrm{ai}}-$ ions of average dimension, and $\boldsymbol{j}_{\text {hi }}$ - heavy ions. The problem, which current mainly contributes to the total electric current $\boldsymbol{j}_{\text {tot }}$, is considered in many books and articles. A detailed analysis is presented in Smirnov (1992). It is shown that the current of light ions has the maximum value. Its vertical component reads

$j_{\mathrm{li}}=e \mu_{\mathrm{li}} E n_{\mathrm{li}}$.

Here $n_{\mathrm{li}}$ is the density of the light ions, and $\mu_{\mathrm{li}}-$ their mobility. Experimental values of $\mu_{\mathrm{li}}$ for positive ions are in the interval of $0.05-5 \mathrm{~cm}^{2} \mathrm{~V}^{-1} \mathrm{~s}^{-1}$. In case of negative ions, we have to do with 1.3-1.4 times larger mobilities (Pulinets and Boyarchuk, 2004). In the following estimates, it is taken $\mu_{\mathrm{li}}=1.3 \mathrm{~cm}^{2} \mathrm{~V}^{-1} \mathrm{~s}^{-1}$.

The mobility of the light ions grows with the height above the Earth's surface due to the decrease of the density of the neutral molecules and the increase of the mean free path of the particles. As a result, the electric current also grows, which causes a decrease of the charge separation. But the velocity of the downward propagating large aerosols also grows with the altitude due to the lowering of the density of the neutral molecules and, consequently, the viscosity decreases. The contributions of these processes, in general, compensate one another. Therefore, as a result, the electric field in the local Frenkel area may be as strong as the field near the Earth's surface (Liperovsky et al., 2008a).

The electric fields generated by charge separation in the atmosphere accelerate the charged particles. For instance, the electrons having a mean free path of about $l_{\text {free }} \approx 0.5 \times$ $10^{-6} \mathrm{~m}$ gain a kinetic energy of 
$\Delta W=l_{\text {free }} e E$.

If $\Delta W$ is larger than the excitation energy $h v=h c / \lambda$ of the atoms and molecules of the atmosphere, the accelerated electrons may excite these particles ( $c$ is the speed of light, $h$ the Planck constant). The particles absorb photons with wavelengths

$\lambda \geq \frac{h c}{\Delta W}$.

For electric fields of $5 \times 10^{4} \mathrm{Vm}^{-1}$, the wavelengths satisfy the relation $\lambda \geq 3.6 \mu \mathrm{m}$. Thus, in case of electric fields of $10^{4}-10^{5} \mathrm{Vm}^{-1}$, the electron energy may be sufficient for the excitation and further emission of quanta of energy in the IR region, which corresponds to the vibrational spectral bands of the molecules $\mathrm{N}_{2} \mathrm{O}, \mathrm{CH}_{4}, \mathrm{CO}, \mathrm{CO}_{2}, \mathrm{O}_{3}$ and $\mathrm{NO}_{2}$ of the atmosphere at wavelengths of $7-15 \mu \mathrm{m}$.

In case of electrons in the atmosphere at the Earth's surface and $E=10^{5} \mathrm{Vm}^{-1}$, one has $\Delta W=0.05 \mathrm{eV}$. At altitudes of $10 \mathrm{~km}$, the additional energy of the electrons $\Delta W$ is about $0.5 \mathrm{eV}$. After a few successive elastic collisions in the electric field $E$, the electron may gain a rather large amount of energy. The maximum value of the energy may amount to $100 \Delta W \approx 5 \mathrm{eV}$. On average, after a trajectory of about 2500 mean free paths, the electron clings to a molecular oxygen molecule. It has to be mentioned that the electron attachment only occurs during the collision of three particles. Consequently, at altitudes of $10-15 \mathrm{~km}$, where the mean free path is about ten times larger than at the Earth's surface and three-particle collisions seldom occur, an electron may have a total trajectory which is two orders longer and gains some tenths of eV.

Further, it is known that at altitudes of about $10 \mathrm{~km}$, during the heating of light ions in the electric field, one may also obtain - in the tail of the ion velocity-distribution functions an essential part of particles with energies of the order of 0.1$0.2 \mathrm{eV}$. This energy is also sufficient for the excitation and further emission of photons with wavelengths of $7-15 \mu \mathrm{m}$.

It has to be underlined that the main part of the energy of the earthquake precursors, according to the proposed mechanism, comes from the atmosphere. The intensification of the earthquake precursor signal is caused by the atmospheric energy.

Next, the accelerated formation of water aerosols before earthquakes also causing IR emissions has to be mentioned. For example, under the action of ionizing radiation (e.g. by radon) and by charge transfer, in the atmosphere occur molecular oxygen ions $\mathrm{O}_{2}^{+}$. But because of the oxygen affinity to electrons, during time scales of $10^{-7} \mathrm{~s}$ (Pulinets and Boyarchuk, 2004), negative ions $\mathrm{O}_{2}^{-}$are obtained. On the other hand, also positively charged ions like $\mathrm{NO}_{2}^{+}$appear in the air. Both negative $\left(\mathrm{O}_{2}^{-}\right)$and positive $\left(\mathrm{NO}_{2}^{+}\right)$ions attract water molecules (having a noticeable dipole moment) and quickly form light ions. The average time of life of the built water complexes has a comparatively long duration and lasts about tenths-hundreds of minutes (Smirnov, 1992). Of importance is that the binding energy of the water molecules to the initial ion is on the order of $0.5 \mathrm{eV}$. This energy may be transformed either into the energy of the thermal motion of the atmospheric particles or into the energy of IR photons emitted during the binding process. Most likely, the emission possesses a continuous spectrum (and no line-spectrum). It will be added to the emission spectrum caused by the electric field (described above), which consists of single spectral lines. Thus, by the water binding energy as well, an increase of the signal of the earthquake precursor may occur. The energy of the IR signal again originates from the atmosphere and causes an increase in the main precursor effect above the earthquake preparation region.

Here, it has yet to be mentioned that the IR emissions occurring at altitudes of $10-15 \mathrm{~km}$ may be observed by satellites, while IR emissions from the near-earth layers are practically absorbed by the atmosphere.

\section{Recent experiments to prove the non-stationary Frenkel generator model}

\subsection{SRINP laboratory works}

Recently, at the Scientific Research Institute of Nuclear Physics (SRINP) of the Moscow Lomonossow State University, the investigation of atmospheric sources of IR emissions predicted by the model of the non-stationary Frenkel generator (Sect. 2) is performed experimentally. IR spectra expected to be intensified before seismic shocks because of the action of electric fields of $2 \times 10^{2}-10^{6} \mathrm{Vm}^{-1}$ during earthquake preparation times are studied. In other words, changes of the intensity of atmospheric IR spectra in the air above seismo-active regions are analysed under laboratory conditions.

During the laboratory experiments, IR emission spectra in a broad band of wavelengths predicted by the theoretical model are considered. Products of plasma-chemical reactions are studied, above all nitrogen and oxygen compounds. We attempt to analyse the form changes of the absorption and emission spectra due to the vibrational energy levels of atmospheric molecules. Into the discharge chamber, different amounts of material containing oxygen, hydrogen and carbon compounds are put into a constant electric field with an intensity of up to $10^{5} \mathrm{Vm}^{-1}$. As result of the performed research, the spectral intervals of the IR emissions at weak changes of the compounding of the atmosphere are determined.

To perform the experiment, a facility for the registration of the absorption and emission spectra in the wavelength interval between $0.3 \mu \mathrm{m}$ and $16 \mu \mathrm{m}$ is established. The experiment may be performed at pressures between $0.1 \mathrm{~atm}$ and $1.0 \mathrm{~atm}$. The insertion of the various gases, aerosols and fluids into the working chamber and into the absorption cell are controlled. 
In the working chamber and in the absorption cell, which are filled with atmospheric air and one of the materials $\mathrm{O}_{2}, \mathrm{~N}_{2}$, $\mathrm{CO}_{2}, \mathrm{O}_{3}, \mathrm{CH}_{4}, \mathrm{~N}_{2} \mathrm{O}, \mathrm{NO}_{2}, \mathrm{CO}, \mathrm{H}_{2} \mathrm{O}$, a discharge is initiated. An optical spectrometer BRUKER IFS $66 \mathrm{~V} / 8$ is used to study both emission and absorption spectra.

Based on the results of the laboratory experiments, we plan to construct a simple special IR spectrometer which will observe the IR emissions in seismo-active regions on Kamchatka and in Tadzhikistan.

\subsection{Proposed scanning of Frenkel areas}

The verification of the proposed infrared hypothesis has to be performed by laboratory experiments as well as by Earthbased and satellite observations. This is, for instance, possible on Kamchatka. We also planned to develop equipment for the analysis of spectra in the IR region processing data of spheric scanning of the atmosphere on Kamchatka, and to perform the first observations (Liperovsky et al., 2009).

Obviously, one has to observe the Frenkel areas which, according to the hypothesis, are situated at altitudes of 10$15 \mathrm{~km}$, where the mean free path of the molecules is approximately one order of magnitude larger than at the Earth's surface, and where the proposed heating mechanism of electrons, with energies of more than $0.45 \mathrm{eV}$ and of light ions in the tail of their distribution function, works effectively in the electric field.

By scanning, the determination of the coordinates and the estimation of the dimensions of the Frenkel areas are possible. Based on the maximum brightness of the images and the numbers of these areas, it seems possible to estimate the magnitude of an imminent earthquake.

To identify earthquake precursors during regular observations of the IR emissions of the night-time atmosphere in seismoactive regions, we propose to scan the atmosphere up to altitudes of $10-15 \mathrm{~km}$. As the intensities of the registered signals will be small, we foresee the observation of the spectra and the intensity of the emissions with the help of two apparatuses working in the regime of data acquisition. Taking former earthquake observations into account, linear cloudy structures were observed at altitudes of 6-10 km, and suggest the searching for earthquake precursors in the form of cloudy curtain type structures with thicknesses much smaller than the horizontal dimensions, which are situated at altitudes up to $10-15 \mathrm{~km}$. The special form of the cloudy structure will be determined by the local upward air flows. The structures may be caused by the intensive emanation of radon along fracture regions and the additional transport by horizontal winds.

In Table 1, the absorption spectra of atmospheric gases in the IR region between $0.7 \mu \mathrm{m}$ and $20 \mu \mathrm{m}$ are shown, which are of interest for the discussed earthquake prediction problem.

Homeopolar molecules $\left(\mathrm{O}_{2}, \mathrm{~N}_{2}\right)$ possess absorption spectra only in the short-wavelength ultraviolet part of the spectrum. They do not absorb in the whole visible and the
Table 1. Spectra of atmospheric gases in the IR region, which are of interest for earthquake prediction. The bold face numbers are of maximum importance for the present experiment.

\begin{tabular}{|c|c|c|}
\hline $\begin{array}{l}\text { gaseous } \\
\text { component } \\
\text { of the air }\end{array}$ & $\begin{array}{l}\text { wavelength }(\mu \mathrm{m}) \\
\text { of centre of main } \\
\text { absorption band }\end{array}$ & comment \\
\hline methan $\mathrm{CH}_{4}$ & 4.3, 7.7, & $\begin{array}{l}\text { transitions between } \\
\text { vibrational levels }\end{array}$ \\
\hline $\begin{array}{l}\text { nitrous oxide } \\
\mathrm{N}_{2} \mathrm{O}\end{array}$ & $4.6,7.8,9.6$ & $\begin{array}{l}\text { overtone bands, } \\
\text { frequencies of the atomic } \\
\text { motions in the molecule }\end{array}$ \\
\hline $\begin{array}{l}\text { carbon } \\
\text { monoxide } \mathrm{CO}\end{array}$ & 4.7 & \\
\hline $\begin{array}{l}\text { carbon } \\
\text { dioxide } \mathrm{CO}_{2}\end{array}$ & $\begin{array}{l}4.3,4.8,5.2 \\
9.4, \mathbf{1 0 . 4}-\mathbf{1 5 . 0}\end{array}$ & $\begin{array}{l}\text { many fine structure lines } \\
\text { near the } 15 \mu \text { m-band, } \\
\text { many vibrational- } \\
\text { rotational bands }\end{array}$ \\
\hline ozone $\mathrm{O}_{3}$ & $\begin{array}{l}4.8,5.8,9.1,9.6 \\
\mathbf{1 4 . 1}\end{array}$ & $\begin{array}{l}\text { overtones, vibrational } \\
\text { frequencies of the } \\
\text { atoms of the molecule }\end{array}$ \\
\hline $\begin{array}{l}\text { nitrogen } \\
\text { dioxide } \mathrm{NO}_{2}\end{array}$ & 13.3 & \\
\hline
\end{tabular}

short-wavelength IR regions of the spectrum. The corresponding emission spectra of the homeopolar molecules are also broadband. Predominantly, they consist of single spectral lines.

Also atomic hydrogen $\mathrm{H}$, radon $\mathrm{Rn}$, and helium $\mathrm{He}$ do not have absorption bands in the 7-20 $\mu \mathrm{m}$ region of interest for earthquake prediction.

Further, the concentration of the water vapour in the atmosphere may change considerably. Thus, variations of the emission in the $7.1 \mu \mathrm{m}$ band by water seem not to be so important for the solution of the earthquake prediction problem.

Thus, altogether, the infrared emission spectra of the regions of strong electric field in the Frenkel system must be distorted and broadened in comparison with the absorption spectra. Of course, one may expect a difference in the "portrait of the IR-spectrum" in the proposed intervals for different seismo-active regions - analogous to the differences of the seismo-ionospheric phenomena in different areas. Besides, identification problems might occur regarding the spectral lines because of the influences of small intermixtures.

Observing Frenkel areas at altitudes between $5 \mathrm{~km}$ and $15 \mathrm{~km}$, apparently the main effect is expected in the spectral interval of IR transparency at 7-9 $\mu \mathrm{m}$ and $10.3-15.0 \mu \mathrm{m}$, as at $9.6 \mu \mathrm{m}$ a strong absorption band occurs in the spectrum. Under cloudy conditions, the atmosphere is transparent only in the $7-8 \mu \mathrm{m}$ region. 


\section{Discussion of the results and conclusions}

Before earthquakes, the formation of mosaic-likely distributed regions of increased ionisation, strong quasistationary electric fields, and IR-emissions in the atmosphere above seismo-active regions where fracturing occurs is possible. In the present work, it is shown that the variations of the electric fields by both the viscous forces of the air and the acceleration of the aerosols in the electric field, may be of the same order. Taking into account the upward air flows in the theoretical model, one should find areas of IR-emissions at altitudes up to $15 \mathrm{~km}$.

The preparation of the distant monitoring of the theoretically predicted IR emissions in the transparency regions with wavelengths of 7-9 $\mu \mathrm{m}$ and $10.3-15 \mu \mathrm{m}$ began. Scanning observations of IR-emissions will be performed from two different points having a distance of $10-40 \mathrm{~km}$ from one another. One expects the occurrence or intensification of IR emissions within the spectral bands of $\mathrm{CO}, \mathrm{CO}_{2}, \mathrm{NO}_{2}, \mathrm{CH}_{4}$ and $\mathrm{O}_{3}$ in the mosaic-likely distributed emitting areas in the atmosphere above earthquake preparation regions.

The Frenkel area observation described in the present work is a ground-based one. Of course, as electric fields in the D-layer may be observed by satellites, the observation of the Frenkel areas should also be possible by satellites - analogously to the observation of D-layer disturbances by radiation belt electron precipitation before seismic shocks (see, for example, Anagnostopoulos et al., 2011; Ouzounov et al., 2008). To distinguish the effect of the Frenkel areas from that of radiation belt electrons, other atmospheric parameters have to be registered at the same time like the Dst-index and VLF waves causing the precipitation.

Acknowledgements. The authors kindly thank G. C. Anagnostopoulos and another anonymous referee for constructive comments.

Edited by: K. Eftaxias

Reviewed by: G. C. Anagnostopoulos, J. Blecki and S. Potirakis

\section{References}

Anagnostopoulos, G., Rigas, V., and Vassiliadis, E.: Radiation belt electron precipitation in the upper ionosphere at middle latitudes before strong earthquakes, 23 pp., arXiv:1012.3588v1, 2011.

Chadha, R. K., Pandey, A. P., and Kuempel, H. J.: Search for earthquake precursors in well water levels in a localized seismically active area of reservoir triggered earthquakes in India, Geophys. Res. Lett., 30, 69-71, 2003.

Derr, J. S.: Earthquake light: a review of observations and present theories, Bull. Seism. Soc. Am., 63, 2177-2187, 1973.

Ermakov, V. I. and Stoshkov, Yu. I.: Cosmic rays in the mechanism of thundercloud production, Bulletin of the Lebedev Physics Institute, 1, 23-35, 2003.

Eshov, B. V. and Uzhenko, L. I.: Mapping of tectonic structures in the form of cloudy and icy covers, Morphological-structural investigations in the Far East, Wladiwostok, 114-119, 1983.
Fidani, C.: The earthquake lights (EQL) of the 6 April 2009 Aquila earthquake, in Central Italy, Nat. Hazards Earth Syst. Sci., 10, 967-978, doi:10.5194/nhess-10-967-2010, 2010.

Frenkel, Y. I.: Theory of atmospheric electricity phenomena, GITTL, Moscow-Leningrad, 1949.

Freund, F. T., Kuhlaci, I. G., Cyr, G., Ling, J., Winnick, M., Tregloan-Reed, J., and Freund, M. M.: Air ionisation at rock surfaces and pre-earthquake signals, J. Atmos. Sol.-Terr. Phys., 71, 1824-1834, doi:10.1016/j.jastp.2009.07.013, 2009.

Freund, F. T., Takeuchi, A., Lau, B. W. S., Al-Manaseer, A., Fu, C. C., Bryant, N. A., and Ouzounov, D.: Stimulated infrared emission from rocks: assessing a stress indicator, eEarth, 2, 7-16, doi:10.5194/ee-2-7-2007, 2007.

Gorny, V. I., Sal'man, A .G., Tronin, A. A., and Shilin, B.V.: Infrared emission of the earth - indicator of seismic activity, Dokl. Akademii Nauk SSSR, 301, 67-69, 1988.

Grigoriev, A. I., Gershenson, N. I., and Gokhberg, M. B.: On the nature of the luminosity of the atmosphere during earthquakes, Doklady Academyi Nauk SSSR, 300, 1087-1090, 1988.

Hedervari, P. and Noszticzius, Z.: Recent results concerning earthquake lights, Ann. Geophys., 3, 705-708, 1985.

Heinke, J., Koch, H., and Martinelli, G.: $\mathrm{CO}_{2}$ and radon measurements in the Vostland (Germany) - a contribution to earthquake prediction research, Geophys. Res. Lett., 22, 749-774, 1995.

Liperovsky, V. A., Pokhotelov, O. A., and Shalimov, S. L.: Ionospheric precursors of earthquakes, Nauka, 1992.

Liperovsky, V. A., Meister, C.-V., Liperovskaya, E. V., Davidov, V. F., and Bogdanov, V. V.: On the possible influence of radon and aerosol injection on the atmosphere and ionosphere before earthquakes, Nat. Hazards Earth Syst. Sci., 5, 783-789, doi:10.5194/nhess-5-783-2005, 2005.

Liperovsky, V. A., Mikhailin, V. V., Shevtsov, B. M., Umarkhodgajev, P. M., Bogdanov, V. V., and Meister, C.-V.: Electrical phenomena in aerosol clouds above faults regions before earthquakes, Proc. 4th Int. Conf. "Solar-Earth connections and earthquake precursors" in Paratunka (Kamchatka region), 14-17 August 2007, edited by: Shevtsov, B. M., IKIR FEB RAS, 391-398, 2007a.

Liperovsky, V. A., Mikhailin, V. V., Davydov, V. F., Bogdanov, V. V., Shevtsov, B. M., and Umarkhodgajev, P. M.: On the infrared emission in the atmosphere before earthquakes, Geophys. Res., 8, 51-68, 2007b.

Liperovsky, V. A., Meister, C.-V., Liperovskaya, E. V., and Bogdanov, V. V.: On the generation of electric field and infrared radiation in aerosol clouds due to radon emanation in the atmosphere before earthquakes, Nat. Hazards Earth Syst. Sci., 8, 1199-1205, doi:10.5194/nhess-8-1199-2008, 2008a.

Liperovsky, V. A., Pokhotelov, O. A., Meister, C.-V., and Liperovskaya, E. V.: Physical models of coupling in the lithosphereatmosphere-ionosphere system before earthquakes, Geomag. Aeronomy, 48, 795-806, 2008b.

Liperovsky, V. A., Umarkhodjaev, P. M., Mikhailin, V. V., Bogdanov, V. V., Maltsev, S. A., Liperovskaya, E. V., Kaisin, A. V., and Lexsina, E. G.: The method of searching of earthquake precursors on the base of remote sensing of local electric fields in the atmosphere, Seis. Instrum., 45, 58-68, 2009.

Liperovskaya, E. V., Meister, C.-V., Biagi, P.-F., Liperovsky, V. A., and Rodkin, M. V.: Influence of very-long-distance earthquakes on the ionosphere? Annales of Geophysics, special issue 
1, Earthquake precursor research: ground and satellite observations, edited by: Biagi, P.-F., Hayakawa, M., Contadakis, M. E., submitted, 2011.

Meister, C.-V., Mayer, B., Dziendziel, P., Fülbert, F., Hoffmann, D. H. H., and Liperovsky, V. A.: On the acoustic model of lithosphere-atmosphere-ionosphere coupling before earthquakes, Nat. Hazards Earth Syst. Sci., 11, 1011-1017, doi:10.5194/nhess-11-1011-2011, 2011.

Mihailin, V. V., Liperovsky, V. A., Silina, A. S., Bogdanov, V. V., Meister, C.-V., and Liperovskaya, E. V.: Generation of electric field and infrared radiation in the troposphere before earthquakes, Proc. 5th Int. Conf. "Solar-terrestrial links and physics of earthquake precursors" Paratunka/Kamchatka, session 5: "Physics of Earthquake Precursors", 2-7 August 2010, edited by: Shevtsov, B. V. and Bogdanov, V. V., IKIR FEB RAS, PetropavlovskKamchatsky, 402-406, 2010.

Mikhailov, Yu. M., Mikhailovna, G. A., Kapustina, O. V., Buzevich, A. V., and Smirnov, S. E.: Power spectrum features of near-earth atmospheric electric field in Kamchatka, Ann. Geophys., 47, 237-245, 2004.

Mikhailov, Yu. M., Mikhailovna, G. A., Kapustina, O. V., Buzevich, A. V., and Smirnov, S. E.: Special features of atmospheric noise superimposed on variations in the quasistatic electric field in the Kamchatka near-earth atmosphere, Geomag. Aeronomy, 45, 649-665, 2005.

Molchanov, O. and Hayakawa, M.: Seismo-electromagnetics and related phenomena: History and latest results, TERRAPUB, Tokyo, 190 pp., 2008.

Ouzounov, D., Habib, S., and Ambroze, S.: Multisensor approach analyzing atmospheric signals for possible earthquake precursors. Application of remote sensing for risk management, Int. Disaster and Risk Conf., Davos, Tudor Rose, 162-165, 2008.

Papadopoulos, G. A.: Luminous and fiery phenomena associated with earthquakes in the East Mediterranean, atmospheric and ionospheric electromagnetic phenomena associated with earthquakes, edited by: Hayakawa, M., TERRAPUB, Tokyo, 559$575,1999$.

Pulinets, S. A. and Boyarchuk, K. A.: Ionospheric precursors of earthquakes, Springer, Berlin, Heidelberg, New York, 2004.

Pulinets, S. A., Boyarchuk, K. A., Hegai, V. V., and Karelin, A. V.: Conception and model of seismo-ionosphere-magnetosphere coupling, Seismo-Electromagnetics: Lithosphere-AtmosphereIonosphere Coupling, edited by: Hayakawa, M., Tokyo, TERRAPUB, 353-361, 2002.

Pulinets, S. A., Ouzounov, D., Karelin, A. V., Boyarchuk, K. A., and Pokhmelnykh, L. A.: The physical nature of thermal anomalies observed before strong earthquakes, Phys. Chem. Earth, 31, 143$153,2006$.
Quing, Z., Xiu-Deng, X., and Chang-Gong, D.: Thermal infrared anomaly - precursor of impending earthquakes, Chinese Sci. Bull., 36, 319-323, 1991.

Rulenko, O. P.: Immediate earthquake precursors in lower atmospheric electricity, Volcanol. Seismol., 4, 57-68, 2000.

Rulenko, O. P., Druzhin, G. I., and Vershinin, E. F.: Atmospheric electric field and natural electromagnetic radiation: measurements prior to the Kamchatka earthquake, November 13, 1993 , M=7.0, Doklady Earth Sci., 349, 832-835, 1996.

Rusanov, A. I.: Theory of phenomena of atmospheric electricity, GITTL, Moscow, Leningrad, 1978.

Shalimov, S. L. and Gokhberg, M. B.: Lithosphere-ionosphere coupling mechanism and its application to the earthquake in Iran on June 20, 1990: A review of ionosphere measurements and basic assumptions, Phys. Earth Planet. Inter., 105, 211-218, 1998.

Slivinsky, A. P., Terekhov, A. S., and Liperovsky, V. A.: Geophysical radar for the observation of ionized clouds in the athmosphere above the earthquake preparation region, Seismic Instr., 45, 2125,2009

Smirnov, S. E.: Characteristics of negative anomalies in the quasistatic electric field in the near-earth atmosphere on Kamchatka, Geomag. Aeronom., 45, 265-270, 2005.

Smirnov, V. V.: Formation of condensation kernels in regions with increased ionisation, Trudy Instituta Mekhaniki, 24, 80-98, 1980.

Smirnov, V. V.: Ionisation in the troposphere, Gidrometeoizdat, St. Petersburg, 1992.

Sobolev, G. A. and Demin, V. N.: Mechanical-electrical phenomena in the earth, Nauka, Moscow, 1980.

Sorokin, V. M. and Chmyrev, V. M.: Electrodynamic model of ionospheric precursors of earthquakes and certain types of disasters, Geomag. Aeronom., 42, 784-793, 2002.

Sorokin, V. M. and Yaschenko, A. K.: Perturbation of a quasisteady electric field in the atmosphere above seismically active areas, Chem. Phys. Reports, 19, 1189-1208, 2000.

Sorokin, V. M., Chmirev, V. M., Pokhotelov, O. A., and Liperovsky, V. A.: Review of the models of lithosphere-ionosphere links during earthquake preparation processes, in: Shortterm prognosis of disastrous earthquakes using radiophysical ground-based and space methods, Proceedings of the Conference, Moscow, 2-3 October 1997, edition of Schmidt United Institute of Physics of the Earth, RAS, edited by: Strakhov, V. N. and Liperovsky, V. A., 64-88, 1998.

Voinov, V. V., Gufel'd, I. L., Kruglikova, V. V., Marenko, V. F., Miranjan F. P., and Ledovskyi, I. S.: Effects in the ionosphere and atmosphere before the Spitak earthquake on December 7, 1988, Izvestiya Akademii Nauk SSSR, Fizika Zemli, 3, 96-101, 1992. 